\title{
EDITORIAL
}

\section{Fasting or Starving our Patients to an Inhumane Extent? A Plea for Some Common Sense}

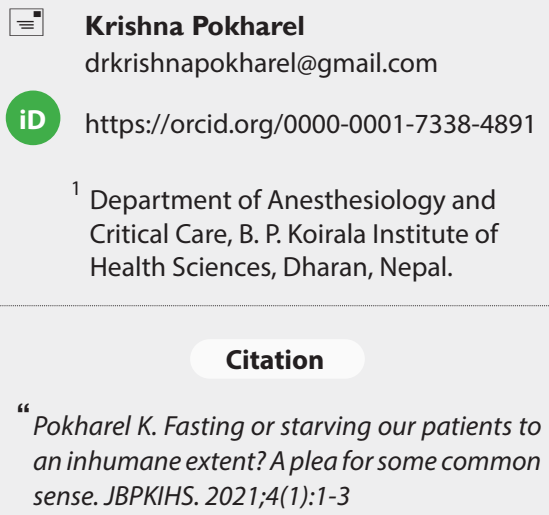
Critical Care, B. P. Koirala Institute of Health Sciences, Dharan, Nepal.

Citation

“Pokharel K. Fasting or starving our patients to an inhumane extent? A plea for some common sense. JBPKIHS. 2021;4(1):1-3

doi https://doi.org/10.3126/jbpkihs.v4i1.36337

\section{(c) (1) () $\Theta$}

This work is licensed under a Creative Commons AttributionNonCommercial 4.0 International License.
- Krishna Pokharel ${ }^{1}$

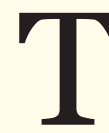
The majority of nil per os (NPO) orders in Nepal are non-compliant with the guidelines for fasting before elective surgery and procedural sedation as $6 \mathrm{~h}$ for solid meal, $4 \mathrm{~h}$ for liquid diet and $2 \mathrm{~h}$ for clear liquids [1]. Although the evidence is growing in favor of pushing the limits of this 6-4-2 rule and liberalizing the fasting guidelines further, our patients are still advised NPO after midnight and kept hungry and thirsty irrespective of when they are scheduled for anesthesia or sedation the next day [2]. For those placed last in the list, the starving duration frequently exceeds $16 \mathrm{~h}$ without a drink before they receive anesthesia and extends beyond surgery [3]. Apart from the distressing aspect of awaiting a procedure, a starved patient may develop hypoglycemia, ketoacidosis, hypovolemia, discomfort, hunger, thirst, grumpiness, and cardiovascular instability on induction of anesthesia [4-7]. Prolonged starving may amplify the organic response to trauma, by increasing insulin resistance, and the loss of lean body mass $[4,8]$.

The current fasting recommendations from prominent specialty societies are largely consensus-driven [8-10]. The rationale behind keeping the patients starved was to keep the stomach empty, and thus, to reduce the aspiration risk. However, the stomach is neither full nor empty during induction of anesthesia because of the dynamic nature of its state [10]. Gastric residual volume (GRV) is dependent on the time and amount of food devoured, emptying rate and secretions from oral cavity and stomach. Gastric emptying is further regulated by hormonal, neuronal, and metabolic feedback [11]. Current evidence has unraveled the disconnect between GRV and fasting duration/ aspiration risk [12-14]. The stomach is very distensible and can accommodate up to $1 \mathrm{~L}$ before intragastric pressure increases. Therefore, an ideal fasting time, or a critical GRV is like a riddle wrapped in a mystery inside an enigma. The only key to this riddle is recording the time of the last meal or drink against the GRV assessed by point-of-care stomach ultrasound before general anesthesia $[15,16]$. This may help us unravel the secret relationship, if there is any, among fasting time, GRV, and pulmonary aspiration in the years to come.

\section{Declarations}


Interestingly, the incidence of pulmonary aspiration as a result of gastric regurgitation is strikingly low in modern practice with recently reported rates of 0.014 to $0.021 \%$ in adults undergoing procedural sedation and $0.01 \%$ in adults undergoing general anesthesia [5, 17-20]. The proven risk factors for aspiration include emergency surgery, light anesthesia/ unexpected response to stimulation, upper/ lower gastrointestinal pathology, improper patient positioning, and the choice of airway management [9]. Realizing the unclear benefit of either food or liquid restriction, with a greater contributing factor being prior identification of patients with risk factors, many facilities in the west have embraced more liberal fasting approaches [8, 9, 13]. Since the liquid aspirations are not as harmful as solid aspirations and may not result in any long-term sequelae, newer fasting guidelines are more liberal towards liquids [16, 20-22]. Clear fluids until called to the operating suite or the 6-4-o regimen could be a better approach to preoperative fasting especially in routine pediatric anesthetic practice [20, 21]. Removing the time limit for clear fluids reduces the incidence of extended preoperative fasting. The enhanced recovery after surgery regimens also encourages carbohydrate drinks up to $2 \mathrm{~h}$ before the induction of anesthesia to maintain hydration to improve insulin sensitivity, and indices of patient comfort following surgery, especially hunger, thirst, malaise, anxiety and nausea [8].
Ultrasound and Magnetic Resonance Imaging-based studies have revealed that a light meal, even if it includes solids, are reduced to negligible amounts in the stomach within $4 \mathrm{~h}[23,24]$. With these recent developments, children are encouraged to eat milkbased products such as yoghurt, soup and formula until $4 \mathrm{~h}$ before anesthesia [8]. Questions have also been raised if adding milk in coffee or tea in the morning before surgery really increases GRV [25-27]. At $60 \mathrm{~min}$, the stomach returns to a size similar to that before a drink containing $50 \mathrm{ml}$ of milk is consumed [28]. Newer, more liberal approaches advocate $20 \%$ milk may be added to clear drinks [28].

The evolving evidence echo that our practice of starving our patients is not only outdated but also harmful and inhumane. It is understandable that both the patients and caretakers do not want to break the fasting norms for fear of the cancellation of surgery. We need multidisciplinary education to break that fear. We are all aware of the frequent need for last-minute changes to the theater schedule, which become very problematic if patients are unfasted. "Clear fluids anytime" potentially resolves this issue. It is a high time we replace a common "NPO now" order with the specific "NPO start time" order based on the scheduled time of the patient's procedure. This is a sincere plea for a commitment from everyone concerned to end the epidemic of starving our patients before anesthesia or sedation.

\section{References}

I. Practice guidelines for preoperative fasting and the use of pharmacologic agents to reduce the risk of pulmonary aspiration: application to healthy patients undergoing elective procedures: an updated report by the American Society of Anesthesiologists Task Force on Preoperative Fasting and the Use of Pharmacologic Agents to Reduce the Risk of Pulmonary Aspiration. Anesthesiology. 20 17; I26(3):376-93. DOI: 10.1097/ALN.000000000000 I 452.

2. Abola RE, Gan TJ. Preoperative fasting guidelines: why are we not following them?: The time to act is now. Anesth Analg. 2017; I24(4): 104I-3. DOI: I0.12I3/ANE.000000000000I 964.

3. Davies A, Pang WS, Fowler T, Dewi F, Wright T. Preoperative fasting in the department of plastic surgery. BMJ Open Qual. 2018;7(4):e000 |6I. DOI: 10.1136/bmjoq-2017-000161.

4. Xu D, Zhu X, Xu Y, Zhang L. Shortened preoperative fasting for prevention of complications associated with laparoscopic cholecystectomy: a meta-analysis.J Int Med Res. 2017;45(I):22-37. DOI: I0.1|77/03000605|66764|I.

5. Andersson H, Zaren B, Frykholm P. Low incidence of pulmonary aspiration in children allowed intake of clear fluids until called to the operating suite. Paediatr Anaesth. 2015;25(8):770-7. DOI: I0.IIII/pan. I2667.

6. Kratz T, Hinterobermaier J, Timmesfeld N, Kratz C, Wulf H, Steinfeldt $\mathrm{T}$, et al. Pre-operative fluid bolus for improved haemodynamic stability during minor surgery:A prospectively randomized clinical trial. Acta Anaesthesiol Scand. 2018;62(9):1215-22. DOI:
10.1 III/aas. I3I57.

7. Al-Robeye AM, Barnard AN, Bew S. Thirsty work: Exploring children's experiences of preoperative fasting. Paediatr Anaesth. 2020;30( I):43-9. DOI: I0.I I I I/pan. I3759.

8. Fawcett WJ, Thomas M. Pre-operative fasting in adults and children: clinical practice and guidelines. Anaesthesia. 2019;74(I):83-8. DOI: I0.I I I I/anae. I 4500.

9. Green SM, Leroy PL, Roback MG, Irwin MG, Andolfatto G, Babl $\mathrm{FE}$, et al. International Committee for the Advancement of Procedural Sedation. An international multidisciplinary consensus statement on fasting before procedural sedation in adults and children. Anaesthesia. 2020;75(3):374-85. DOI: I0.I I I I/anae. I 4892. Erratum in:Anaesthesia. 2020;75(6):818.

10. Thomas M, Engelhardt T. Think drink! Current fasting guidelines are outdated. Br J Anaesth. 2017;1 I8(3):29I-3. DOI: I0.1093/bja/ aew450.

II. Hellstrom PM, Gryback P, Jacobsson H. The physiology of gastric emptying. Best Pract Res Clin Anaesthesiol. 2006;20(3):397-407. DOI: I0.10I6/j.bpa.2006.02.002.

12. Hakak S, McCaul CL, Crowley L. Ultrasonographic evaluation of gastric contents in term pregnant women fasted for six hours. Int J Obstet Anesth. 2018;34:15-20. DOI: 10.1016/j.ijoa.2018.01.004.

13. Beach ML, Cohen DM, Gallagher SM, Cravero JP. Major adverse events and relationship to nil per os status in pediatric sedation/ anesthesia outside the operating room: a report of the pediatric 
sedation research consortium. Anesthesiology. 2016;124(I):80-8. DOI: I0.1097/ALN.0000000000000933. Erratum in: Anesthesiology. 2016; I 24(5): I 202.

14. Van de Putte P, Vernieuwe L, Jerjir A, Verschueren L, Tacken $M$, Perlas A. When fasted is not empty: a retrospective cohort study of gastric content in fasted surgical patients. $\mathrm{Br} J$ Anaesth 2017; I 18(3):363-7I. DOI: 10.1093/bja/aew435.

15. Charlesworth M, Wiles MD. Pre-operative gastric ultrasound - should we look inside Schrödinger's gut? Anaesthesia. 2019;74(I):I09-12. DOI: I0.IIII/anae. I45I6.

16. Bouvet L, Desgranges FP, Aubergy C, Boselli E, Dupont G, Allaouchiche B, Chassard D. Prevalence and factors predictive of full stomach in elective and emergency surgical patients: a prospective cohort study. Br J Anaesth. 2017; I 18(3):372-9. DOI: 10.1093/bja/ aew462.

17. Green SM, Mason KP, Krauss BS. Pulmonary aspiration during procedural sedation: a comprehensive systematic review. $\mathrm{Br} \mathrm{J} \mathrm{An}-$ aesth. 20I7; I I8(3):344-54. DOI: 10.1093/bja/aex004.

18. Sakai T, Planinsic RM, Quinlan JJ, Handley LJ, Kim TY, Hilmi IA.The incidence and outcome of perioperative pulmonary aspiration in a university hospital: a 4-year retrospective analysis. Anesth Analg. 2006; I03(4):94I-7. DOI: I0.12I3/0I.ane.0000237296.5794I.e7.

19. Beck CE, Rudolph D, Mahn C, Etspüler A, Korf M, Luthke M, et al. Impact of clear fluid fasting on pulmonary aspiration in children undergoing general anesthesia: Results of the German prospective multicenter observational (NiKs) study. Paediatr Anaesth. 2020;30(8):892-9. DOI: I0.I I I I/pan. I3948.

20. Thomas M, Morrison C, Newton R, Schindler E. Consensus statement on clear fluids fasting for elective pediatric general anesthesia. Paediatr Anaesth. 2018;28(5):4 I I-4. DOI: I0. I I I I/pan. I3370.

21. Andersson H, Hellstrom PM, Frykholm P. Introducing the 6-4-0 fasting regimen and the incidence of prolonged preoperative fasting in children. Paediatr Anaesth. 2018;28(I):46-52. DOI: I0. I I I I/ pan. 13282.

22. Warner MA, Warner ME, Warner DO, Warner LO, Warner EJ. Perioperative pulmonary aspiration in infants and children. Anesthesiology. 1999;90(I):66-7I. DOI: 10.1097/00000542-
|9990|000-000| I.

23. Sumpelmann AE, Sumpelmann R, Lorenz M, Eberwien I, Dennhardt $\mathrm{N}$, Boethig D, et al. Ultrasound assessment of gastric emptying after breakfast in healthy preschool children. Paediatr Anaesth. 20I7;27(8):8|6-20. DOI: I0.III I/pan. I3I72.

24. Schmitz A, Kellenberger CJ, Liamlahi R, Fruehauf M, Klaghofer R, Weiss M. Residual gastric contents volume does not differ following 4 or $6 \mathrm{~h}$ fasting after a light breakfast - a magnetic resonance imaging investigation in healthy non-anaesthetised schoolage children. Acta Anaesthesiol Scand. 2012;56(5):589-94. DOI: I0.1 III/j.1399-6576.20II.0260I.x.

25. Larsen B, Larsen LP, Sivesgaard K, Juul S. Black or white coffee before anaesthesia?: A randomised crossover trial. Eur J Anaesthesiol. 20 I6;33(6):457-62. DOI: I0. I097/EJA.0000000000000457.

26. Hillyard S, Cowman S, Ramasundaram R, Seed PT, O'Sullivan G. Does adding milk to tea delay gastric emptying? $\mathrm{Br} J$ Anaesth. 20I4; I I2(I):66-7I. DOI: 10.1093/bja/aet26I.

27. Okabe T, Terashima $\mathrm{H}$, Sakamoto $A$. Determinants of liquid gastric emptying: comparisons between milk and isocalorically adjusted clear fluids. Br J Anaesth. 20I5; I I4(I):77-82. DOI: I0.1093/bja/ aeu338.

28. Du T, Hill L, Ding L, Towbin AJ, Dejonckheere M, Bennett P, et al. Gastric emptying for liquids of different compositions in children. Br J Anaesth. 2017; I 19(5):948-55. DOI: 10.1093/bja/aex340. 